\title{
EVALUATION OF RAMUS AUTOGENOUS BLOCK GRAFT FOR VERTICAL AUGMENTATION OF MANDIBULAR POSTERIOR ALVEOLAR RIDGE
}

\author{
Sara M. Mandour ${ }^{1}$ BDS, Nagy E. Hassan² PhD, Ahmed O. Sweedan ${ }^{3} P h D$
}

\begin{abstract}
INTRODUCTION: Bone defects in the human mandible are common. They are mostly determined by premature loss of teeth due to periodontal disease or traumas. They usually cause reduction of alveolar bone volume, which becomes inconsequence, inadequate for standard treatments with Osseo integrated implants. The predictability of the implant survival and the maintenance of long-term stability of implants in function are directly associated with the quality and quantity of the available bone for implant placement. In the case of alveolar ridges with insufficient bone volume vertical, horizontal or sagittal inter-maxillary relationships, additional surgical procedures can be necessary to reconstruct and augment the deficiency. Bone block graft is the preferred method for many types of augmentation procedures, since it secures both a source of osteogenic cells and a rigid structure for mechanical support. In addition, bone block graft conserves its volume better than particulate grafting.

OBJECTIVES: This study provides a clinical, radiographic, analysis of the use of mandibular ramus block autografts for vertical alveolar ridge augmentation. The suitability of the bone will be harvested to provide sufficient bone volume to facilitate implant insertion at a second stage.

MATERIALS AND METHODS: The present study was conducted on 12 patients with age ranged from20-50 years seeking implantation of their lost posterior mandibular teeth, and have limited bone height. Patients were selected on the basis of history, clinical examination and radiographic examination using panoramic radiography and CBCT.

RESULTS: in this study 10 patient out of 12 showed successful vertical bone augmentation with autogenous bone graft harvested from the ramus of the mandible with $83.33 \%$ success rate.

CONCLUSIONS: using ramus autogenous bone graft in augmentation of vertical bone defects in the posterior area of the mandible has significant success.

KEYWORDS: Alveolar ridge augmentation; Autogenous bone grafts; Endosseous dental implants; Intraoral donor sites.
\end{abstract}

1- BDS, MS, Faculty of Dentistry, Alexandria University, Egypt.

2- Professor of Oral and Maxillofacial Surgery, Department of Oral and Maxillofacial Surgery Faculty of Dentistry, Alexandria University, Egypt.

3- lecturer of Oral and Maxillofacial Surgery, Department of Oral and Maxillofacial Surgery Faculty of Dentistry, Alexandria University, Egypt.

Corresponding author:

E-mail: saramandour52@gmail.com

\section{INTRODUCTION}

In pre-implant surgery, small grafts are often needed. Grafts from the mandible are often recommended, mainly from the symphyseal area, the trigonum or the ascending ramus. The advantages of grafts taken from intraoral sites are that morbidity is usually minimal and distant donor sites can be avoided (1). The drawback is the limited amount of bone available. A harvesting technique described in which the graft was taken from the ramus of the mandible in the area of the oblique ridge (2).

Bone which is predominantly cortical may offer good initial stability at implant placement but is more easily damaged by overheating during the drilling process, especially with sites more than $10 \mathrm{~mm}$ in depth. At the other extreme, bone with a thin or absent cortical layer and sparse trabeculation offers very poor initial implant stability and fewer cells with a good osteogenic potential to promote osseointegration (3-4).

Bone reconstruction techniques have been advanced in order to optimize the esthetic and functional outcome. However, the restoration of the oral function of atrophic alveolar crests still remains a challenge in oral implantology (5). Bone augmentation procedures are often indicated to allow implant placement in an optimal three-dimensional position. The extent of atrophy of the alveolar crest dictates whether the bone augmentation procedures may be performed simultaneously with the implant placement or as a separate procedure (6).

\section{MATERIALS AND METHODS}

\section{Patients}

This prospective observational study included 12 patients treated for 12 vertical defects of the posterior mandible resulting from teeth loss several years ago. They were selected from the Outpatient Clinic of the Department of Oral and Maxillofacial Surgery, Faculty of Dentistry, Alexandria University. These patients were treated with an autogenous bone graft from the ramus; the objective was to create an effective bone height, i.e., adequate bone volume for the insertion of dental implants with a diameter $3.4 \mathrm{~mm}$ and length $9.5 \mathrm{~mm}$, thus avoiding the need for short implants. Inclusion criteria were the following: a resorbed posterior mandible, and patient request for implantsupported restorations.

Patients were fully informed about the treatment procedures and follow up examination. Appropriate institutional ethical clearance and written informed consent were obtained.

The posterior region of the mandible was defined as the area located posterior to the first premolar. The following exclusion criteria were applied prior to surgery: smoking 
habit, poorly controlled diabetes, previous history of radiotherapy, and refusal to provide written informed consent.

\section{Surgical technique}

Patients received antibiotic prophylaxis with $1 \mathrm{~g}$ oral amoxicillin-clavulanic

acid every $12 \mathrm{~h}$, commencing at first day before surgery and continuing for 7 days. The donor and receptor sites were infiltrated with local anaesthetic solution. At the receptor site, a number 15 scalpel was used to make a single crestal incision.

Following this, a full-thickness buccal and crestal flap was elevated to expose the reconstruction area. A corticocancellous block graft was then obtained from same side of the defect was made medial to the external oblique ridge in an anterior direction and terminated in the first molar area to avoid interference with the inferior alveolar nerve branches. The external oblique ridge was dissected free and a ramus exposure had obtained; by pulling the overlying soft tissue was pushed along the ascending ramus. The lateral surface of the mandibular ramus was exposed by blunt dissection, and the periosteum was kept out of the way. The exposed bone area was then evaluated in terms of the amount needed. The margins of the block of bone to be harvested were outlined by holes drilled through the cortex with a small round bur. The anterior vertical osteotomy was performed with a thin fissure bur, just cutting through the cortex until the cancellous bone was identified by marrow bleeding. The inferior osteotomy was not made completely through the cortex. With a bur a groove was created to undermine the lateral cortex so that a fracture would occur at a particular level. After completing all osteotomies, the lateral mandibular bone was fractured off with the aid of one flexible and one stiff straight chisel. The bone block was carefully lifted. The harvested bone was in saline until was particulated with a suitable drill according to the screw size to be placed. The harvested corticocancellous bone block was fixed to the underlying bone with one or two titanium screws. An osteosynthesis screw was used with $2 \mathrm{~mm}$ by 11 screws to ensure bicortical stability in the residual alveolar crest. The site was extensively perforated with a thin drill to enhance the blood supply. Excessive periosteal cuts were made to ensure there would be sufficient length of the mucosal flap to avoid pressure on the grafts, ischemia in the flap, and the risk of wound dehiscence, the flap then was sutured. (Figure 1)

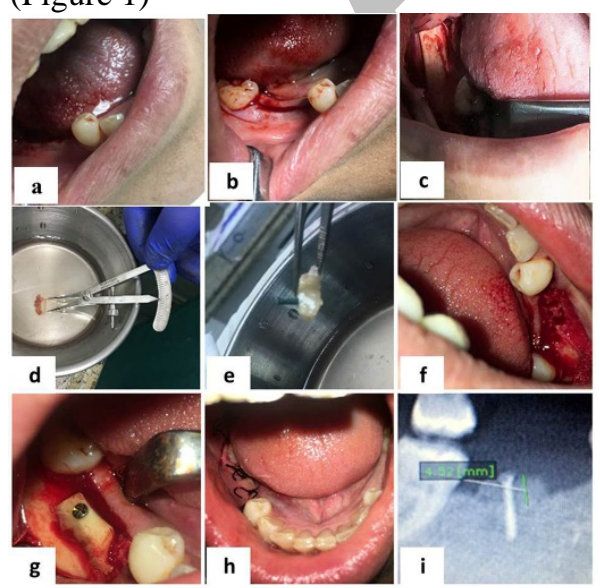

Figure 1: Showing the surgical steps Site of grafting b) flap release c) harvesting the graft d) the autogenous bone e) drilling for screw $\mathrm{f}$ ) decortection $\mathrm{g}$ ) securing the graft by screw $\mathrm{h}$ ) suturing the flap i) immediate post-operative position of the screw

\section{Post-surgical care}

After the surgery, the patients were instructed to apply cold compresses on the surgical sites; and not to brush or irritate it for 10 days, to rinse their mouth with chlorhexidine $0.12 \%$ (Hexitol mouth wash, Arab drug company, Cairo, Egypt) three times a day for 1 week, and to maintain a soft diet for about 6 weeks. Analgesics, diclofenac potassium 50mg, (cataflam 50 mg tablet, Novartis Pharma, Cairo, Egypt) three times daily and antibiotic, amoxicillin-clavulanic acid 1g, (Augmentin 1g, GlaxoSmithKline. Cairo, Egypt) twice daily were prescribed for seven post-operative days.

\section{Clinical Evaluation}

All patients were examined two days, week and two weeks to check for the presence of pain, discomfort, swelling, or infection.

\section{Radiographic Evaluation}

Cone beam computed tomography were taken immediate postoperative and after 6 months to evaluate changes of bone height.

\section{Statistical analysis of the data}

Data were fed to the computer and analyzed using IBM SPSS software package version 20.0. (Armonk, NY: IBM Corp) Qualitative data were described using number and percent. The Kolmogorov-Smirnov test was used to verify the normality of distribution Quantitative data were described using range (minimum and maximum), mean, standard deviation and median.

\section{RESULTS}

In this study 12 patient (5 females and 7 males) having vertical bone defect.

In the posterior zone of the mandible. Their ages ranged between 22 and 52 years with mean age of 36 years. (table 1) They were selected from the Outpatient Clinic of the Oral and Maxillofacial Surgery Department, Faculty of Dentistry, Alexandria University.

Table (1): Distribution of the studied cases according to demographic data $(n=12)$

\begin{tabular}{||c|c|c||}
\hline & No. & \% \\
\hline Sex & \multicolumn{2}{||}{} \\
Male & 7 & 58.3 \\
Female & 5 & 41.7 \\
\hline Age (years) & & \\
$\leq 35$ & 6 & 50.0 \\
$>35$ & 6 & 50.0 \\
\hline Min. - Max. & \multicolumn{2}{|c|}{$22.0-52.0$} \\
Mean \pm SD. & \multicolumn{2}{|c|}{$36.33 \pm 9.34$} \\
Median & \multicolumn{2}{|c|}{37.0} \\
\hline
\end{tabular}

All patients had undergone surgical procedure for vertical bone augmentation. All patients were followed up both clinically and radiographically for 6 months. All patients had been operated under local anesthesia and no complications had been recorded during the operation. All patients had been examined periodically during the followup period up to 6 months. 


\section{I- Clinical evaluation}

- Pain, tenderness, infection or swelling there was no observation of infection after one week and during the follow up period.

- Postoperative edema and discomfort were mild to moderate and ended by the first week. Pain considered being normal after the procedure for 48hrs and four out of twelve patients had experienced pain to the end of the first week.

Two patients showed graft exposure in the second week postoperatively one showed wound dehesience in the first week postoperatively and healed with secondary intention. (Table 2) (Figure 2)

Table (2): Distribution of the studied cases according to complication $(\mathrm{n}=12)$

\begin{tabular}{||l|c|c||}
\hline Complication & No. & \% \\
\hline No & 9 & 75 \\
$\begin{array}{l}\text { Wound } \\
\text { dehiscence } \\
\text { Exposure of graft }\end{array}$ & 1 & 8.3 \\
\hline
\end{tabular}

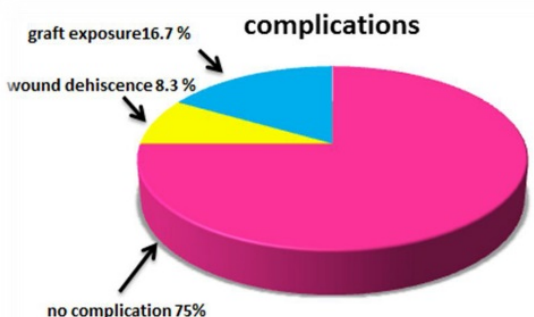

Figure 2: Distribution of the studied cases according to complication $(n=12)$

\section{II- Radiographic evaluation}

Radiographic measurements revealed that an average of 6 $\mathrm{mm}$ of vertical ridge augmentation (range $=5$ to $9 \mathrm{~mm}$, $\mathrm{SD}=1.36$ ) was achieved immediate postoperative and 4.5 $\mathrm{mm}$ (range 3.00 to $7.00 \mathrm{~mm}$, SD $=1.40$ ) after 6 months (Table 3).

The resorption rate according to the radiographic measurements was 25\%. (Figure 3, 4)

Table (3): Comparison between Immediate post-operative and after six months post-operative according to Radiographic bone assessment $(\mathrm{mm})(\mathrm{n}=12)$

\begin{tabular}{||l|c|c|c||}
\hline & $\begin{array}{c}\text { Immediate } \\
\text { post- } \\
\text { operative }\end{array}$ & $\begin{array}{c}\text { After six } \\
\text { months post- } \\
\text { operative }\end{array}$ & p \\
\hline $\begin{array}{l}\text { Radiographic bone } \\
\text { assessment (mm) }\end{array}$ & & & \\
Min. - Max. & $5.0-9.0$ & $3.0-7.0$ & $\mathbf{P}$ \\
Mean \pm SD. & $6.25 \pm 1.36$ & $4.63 \pm 1.40$ & $>\mathbf{P . 0 0 1}$ \\
Median & 6.0 & 4.50 & \\
\hline
\end{tabular}

\section{t: Paired t-test}

$\mathrm{p}$ : $\mathrm{p}$ value for comparing between Immediate postoperative and after six months post-operative was found in significant

$*$ : Statistically significant at $\mathrm{p} \leq 0.05$

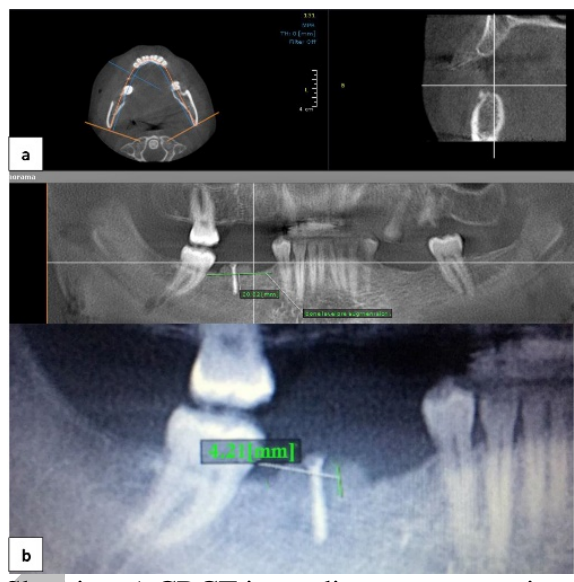

Figure 3: Showing a) CBCT immediate post-operative and b) 6 months post-operative

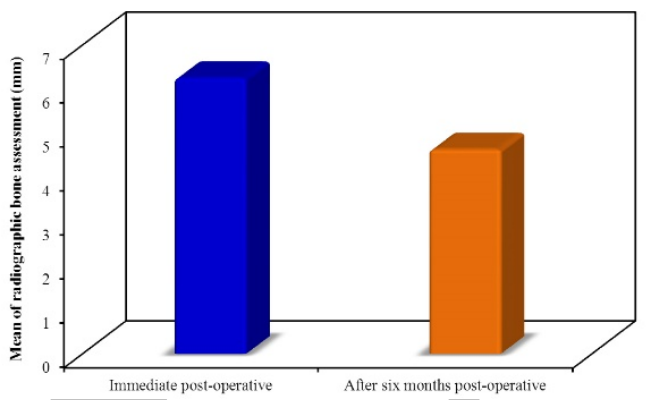

Figure 4: Comparison between Immediate post-operative and after six months post-operative according to Radiographic bone assessment $(\mathrm{mm})(\mathrm{n}=12)$

\section{Statistical analysis}

The results of all measurements were registered on a case record form and were entered into an electronic database to be analyzed statistically. The distributions of data were tested for normality. Comparison between measurements of bone in mm immediate and 6months postoperative done with paired t-test, these differences were statistically in significant $(\mathrm{p}>0.001)$.

\section{DISCUSSION}

In the present study, block grafts were taken from the same side of the ramus by enlarging one of the incisions used to expose the recipient site, thus avoiding the need for a second donor site. The potential of using only one surgical field might help to decrease the overall postoperative morbidity and complication rates $(7,8)$.

This donor site has the advantage of providing bone with minimum resorption and early revascularization and with a low complication rate. Initial graft stability is essential to achieve complete graft immobility and therefore ensure correct neovascularization without fibrous tissue formation. In most cases, fixation of each graft block with one or two microscrews was sufficient to achieve adequate mechanical stability.

Although the number of cases in this study was limited, there were no major complications associated with this technique $(9,10)$.

Although some authors have reported good outcomes using this technique, its utilization in the posterior mandible is associated with an elevated exposure of the graft $(11,12)$.

Rates of up to $40 \%$ for graft exposure and resorption in the mid or long term are the main drawbacks of using onlay bone grafts to treat posterior vertical mandibular defects (13). 
More buccally towarded crestal flaps enabled nontensional primary closure of the wound, reducing the risk of wound dehiscence, and provided adequate coverage of the bone graft thereby limiting graft resorption during the maturation process. Clinical and radiological follow-up has shown good stability of the reconstructions (14).

Cordaro et al. $(15,16)$ reported a $41.5 \%$ loss in bone height in the first 6 months when the chin or mandibular ramus was used as the donor site. Other authors have reported $0-20 \%$ vertical loss of intraoral autogenous grafts in the first 6 months.

While in this study with no use of any membrane the resorption rate was $25 \%$ after 6 months.

Rates of up to $40 \%$ for graft exposure and resorption in the mid or long term are the main drawbacks of using onlay bone grafts to treat posterior vertical mandibular defects (17-19).

Structurally, the ideal graft should have the thinnest possible outer cortical layer and a predominant inner cancellous layer to promote its rapid vascularization and nutrition and to strengthen its mechanical stability at the same time. Appropriate graft immobilization is also important to avoid micromotion and the consequent rupture of vascular buds, which can lead to a failure of graft incorporation into the receptor bed $(20,21)$.

\section{CONCLUSION}

The results of the present study showed that the use of block graft harvested from the ramus of the mandible to augment vertical bone defect in the posterior of the mandible has significant success rates after an observation period of up to 6 months. Further researches are needed using different other technique for harvesting the bone graft and other supportive materials like membranes and osteoinductive synthetic materials.

\section{CONFLICT OF INTEREST}

The authors declare that they have no conflicts of interest.

\section{REFERENCES}

1. Roccuzzo M, Ramieri G, Bunino M, Berrone S. Autogenous bone graft alone or associated with titanium mesh for vertical alveolar ridge augmentation: a controlled clinical trial. Clin Oral Implants Res. 2007;18:286-94.

2. Soehardi A, Meijer GJ, Strooband VF, de Koning M, Stoelinga PJ. The potential of the horizontal ramus of the mandible as a donor site for block and particular grafts in pre-implant surgery. Int J Oral Maxillofac Surg. 2009;38:1173-8.

3. Al-Ardah AJ, Alqahtani F, Lozada JL. Surgical technique for harvesting autogenous mandibular symphysis graft - US Patent 9,265,797, 2016.

4. Stimmelmayr M, Gernet W, Edelhoff D, Güth JF, Happe A, Beuer F. Two-stage horizontal bone grafting with the modified shell technique for subsequent implant placement: a case series. Int $\mathrm{J}$ Periodontics Restorative Dent. 2014;34:269-76.

5. Pommer B, Zechner W, Watzek G, Palmer R. To Graft or not to graft? Evidence-based guide to decision making in oral bone graft surgery. In: Zorzi A, Batista J (eds). Bone grafting. $1^{\text {st }}$ ed. Ch 11. Published online: InTech Open; 2012. p 1-25.
6. Barone A, Ricci M, Mangano F, Covani U. Morbidity associated with iliac crest harvesting in the treatment of maxillary and mandibular atrophies: A 10-year analysis. J Oral Maxillofac Surg. 2011;69:2298-304.

7. Oppenheimer AJ, Tong L, Buchman SR. Craniofacial bone grafting: Wolff's law revisited. Craniomaxillofac Trauma Reconstr. 2008;1:49-61.

8. Sakkas A, Wilde F, Heufelder M, Winter K, Schramm A. Autogenous bone grafts in oral implantology - is it still a "gold standard"? A consecutive review of 279 patients with 456 clinical procedure. Int J Implant Dent. 2017;3:23.

9. Milinkovic I, Cordaro L. Are there specific indications for the different alveolar bone augmentation procedures for implant placement? A systematic review. Int J Oral Maxillofac Surg. 2014;43:606-25.

10. Munoz Garcia J, Vidal Marcos AV, Restoy Lozano A, Gasco Garcia C. Utility of bis-pectral index monitoring during intravenous sedation in the dental office. Int J Oral Maxillofac Implants. 2012;27:375-82.

11.Louis PJ, Gutta R, Said-Al-Naief N, Barto-lucci AA. Reconstruction of the maxilla and mandible with particulate bone graft and titanium mesh for implant placement. J Oral Maxillofac Surg. 2008;66:235-45.

12. Pelo S, Boniello R, Moro A, Gasparini G, Amoroso PF. Augmentation of the atrophic edentulous mandible by a bilateral two-step osteotomy with autogenous bone graft to place osseointegrated dental implants. Int J Oral Maxillofac Surg. 2010;39:227-34.

13. Cordaro L, Torsello F, Accorsi Ribeiro C, Liberatore M, Mirisola di Torresanto V. Inlay-onlay grafting for threedimensional reconstruction of the posterior atrophic maxilla with mandibular bone. Int $\mathrm{J}$ Oral Maxillofac Surg. 2010;39:350-7.

14. Khoury F, Happe A. Soft tissue management in oral implantology: a review of surgical techniques for shaping an esthetic and functional peri-implant soft tissue structure. Quintessence Int. 2000;3:483-99.

15. Cordaro L, Amade DS, Cordaro M. Clinical results of alveolar ridge augmentation with mandibular block bone grafts in partially edentulous patients priorto implant placement. Clin Oral Implants Res. 2002;13:103-11.

16. Proussaefs P, Lozada J. The use of intraorally harvested autogenous block grafts for vertical alveolar ridge augmentation: a human study. Int J Periodontics Restorative Dent. 2005;25:351-63.

17. De Stavola L, Tunkel J. Results of vertical bone augmentation with autogenous bone block grafts and the tunnel technique: a clinical prospective study of 10 consecutive- ly treated patients. Int $\mathrm{J}$ Periodontics Restorative Dent. 2013;33:651-9.

18. Mazzocco C, Buda S, De Paoli S. The tunnel technique: a different approach to block grafting procedures. Int $\mathrm{J}$ Periodontics Restorative Dent. 2008;28:45-53.

19. Ersanli S, Arısan V, Bedeloğlu E. Evaluation of the autogenous bone block transfer for dental implant placement: Symphysal or ramus harvesting? BMC Oral Health 2016;16:4.

20. Schwartz-Arad D, Levin L, Sigal L. Surgical success of intraoral autogenous block onlay bone grafting for alveolar ridge augmentation. Implant Dent. 2005;14:131-8.

21. Laviv A, Jensen OT, Tarazi E, Casap N. Alveolar sandwich osteotomy in resorbed alveolar ridge for dental implants: a 4-year prospective study. J Oral Maxillofac Surg. 2014;72:292-303. 